\title{
The 2013 Malaysian Elections: Ethnic Politics or Urban Wave?
}

\author{
Jason Wei Jian Ng, Gary John Rangel, \\ Santha Vaithilingam, and Subramaniam S. Pillay
}

\begin{abstract}
In this article we examine the electoral impact of urbanization vis-à-vis ethnicity in Malaysia. We employ a robust econometric technique, the fractional response logit model, on data from the recently concluded thirteenth general election. The findings show that there are both an ethnic effect and an urban effect in determining the distribution of parliamentary seats among the political groups. Strong support for the opposition coalition, Pakatan Rakyat, was evident in urban constituencies, while the ruling coalition, Barisan Nasional, continued to enjoy success in rural constituencies. Although Barisan Nasional is still dependent on Bumiputera support, its success is also dependent on non-Bumiputera support from rural constituencies. However, with declining birthrates among the Chinese electorates, this support may not be forthcoming in future elections. We also provide insights for both coalitions to consider in developing strategies for the next election. Kerwords: Malaysia, thirteenth general election, ethnic politics, fractional logit response model, urbanization
\end{abstract}

THERE HAVE BEEN THIRTEEN GENERAL ELECTIONS IN MALAYSIA SINCE IT gained independence from the British in 1957. In all thirteen elections, the same coalition, Barisan Nasional (BN) ${ }^{1}$ or National Front, has been returned to power. The thirteenth general election (GE13), held on May 5,2013 , was the most fiercely contested election in Malaysia's history. For the first time, there was a degree of uncertainty about BN's ability to retain power. The opposition coalition, Pakatan Rakyat (PR) or People's Alliance, which was formed in 2008, appeared to have become credible enough to launch a genuine threat to BN's stranglehold on power. However, in the end, BN retained power with a simple but comfortable majority by winning 133 of the 222 parliamentary constituencies contested. This was a slight reduction from the 138 seats that it won in the previous election held in 2008. This outcome again denied BN the two-thirds 
majority it had enjoyed from independence in 1957 until 2008. By polling only 47.4 percent of the votes cast, it recorded its lowest ever popular support in history.

Peninsular Malaysia was the major battleground where $\mathrm{BN}$ won eighty-five seats against PR's eighty. ${ }^{2}$ While this result was the same as in the 2008 election, there was, however, a notable change in the distribution of the seats. BN regained some of the Malay-dominated rural seats it had lost in 2008, but also lost a number of urban seats in traditional BN strongholds, especially in the southern part of the peninsula. Given that most Chinese Malaysians live in urban areas, Prime Minister Najib Razak subsequently termed this phenomenon the Chinese Tsunami, purportedly reflecting the huge exodus of Chinese voters from BN to PR (Noh 2014).

However, political analysts have observed that while there was an increase in Chinese support for PR, the electoral outcome also saw a major swing in the urban electorate against $\mathrm{BN}$, causing a further widening of Malaysia's rural-urban rift (Boo 2013). One of the PR leaders, Lim Kit Siang, described this as a "Malaysian and urban tsunami" (The Star 2013). This debate of whether the electoral outcome was a result of an urban or a Chinese swing against $\mathrm{BN}$ has been inconclusive due to the high correlation between urban parliamentary constituencies and the proportion of Chinese Malaysian voters in any given constituency.

Against this backdrop, the aim of this study is to identify which of the two factors, ethnicity or urbanization, provides a stronger explanation for the erosion of BN's popular votes in GE13. We measure the proportion of votes won by BN due to urbanization and ethnic factors using a robust econometric technique, the fractional response logit model proposed by Papke and Wooldridge (1996). This model extends the generalized linear model by accounting for the bounded nature of the data, which is a proportion quantity.

The article is organized as follows. We begin by providing a description of the parliamentary system and development of politics in Malaysia since its independence. The next section describes the sources of the data and explains the methodology used to model the proportion of votes won by $\mathrm{BN}$, and how the ethnicity and urbanization impacts can be quantified. We then present and discuss the estimation results, concluding with the implications of the results. This article, however, for reasons explained in the next section, only includes election data from Peninsular Malaysia and excludes the two Borneo states of Sabah and Sarawak. 


\section{Malaysian Politics and the Electoral System}

\section{Historical Background}

Peninsular Malaysia, or Malaya as it was then known, became independent from British colonial rule in 1957. In 1963, Singapore and the Borneo states of Sabah and Sarawak merged with Malaya to form a new nation called Malaysia. However, two years later, Singapore separated from Malaysia due to political differences. Since then, Malaysia consists of thirteen states: eleven in Peninsular Malaysia (i.e., the old Malaya) and the two states of Sabah and Sarawak. ${ }^{3}$

In our study we focus on electoral data only from Peninsular Malaysia for several reasons. First, the main source of economic and political power lies in Peninsular Malaysia due to historical reasons, the level of development, and concentration of population (Khoo 2013). Second, the political parties operating in the Borneo states are to a certain extent autonomous from those in the peninsula (Noor 2013). Thus, there is a distinct possibility that whichever party or coalition wins in the peninsula can persuade politicians who have won on opposition party tickets in Sabah and Sarawak to join their coalition (Yusoff 2001). Finally, the ethnic composition of Sabah and Sarawak is quite different from that of Peninsular Malaysia. In particular, the ethnic makeup of Sabah and Sarawak is much more diverse (Sim 2010). Therefore, ethnic factors exercise a much stronger influence on the electoral outcomes in the peninsula relative to Sabah and Sarawak. Of the 222 federal constituencies, 165 (or nearly 75 percent) are from Peninsular Malaysia. It is for these reasons that this study is confined to the peninsula for the remainder of this article.

Malaysia is ethnically a very diverse nation. The indigenous ethnic groups are classified as Bumiputera (which can be transliterated as "son of the soil") and this classification includes the Malays, Orang Asli (who are the aboriginal people in Peninsular Malaysia), and the various indigenous ethnic groups in the Borneo states of Sabah and Sarawak. According to the 2010 census, the Bumiputera community made up 67.4 percent of the total Malaysian population. The other two major ethnic groups are the Chinese and Indians, who made up 24.6 and 7.3 percent of the population, respectively.

Table 1 presents the population distribution by ethnic groups from 1957 to 2010 in Peninsular Malaysia. As can be seen from the table, at the time of independence in 1957, there was almost equal representation of Malays ${ }^{4}$ and non-Malays. Therefore, there was considerable fear among the Malays that they would be swamped by the Chinese and In- 
Table 1 Population Distribution by Ethnic Group in Peninsular Malaysia, 1957-2010

\begin{tabular}{lrrrrrr}
\hline & 1957 & 1970 & 1980 & 1991 & 2000 & 2010 \\
\hline Malays/Bumiputera & 49.8 & 52.7 & 55.3 & 58.3 & 62.4 & 64.6 \\
Chinese & 37.2 & 35.8 & 33.8 & 29.4 & 27.4 & 25.9 \\
Indians & 11.1 & 10.7 & 10.2 & 9.5 & 9.5 & 8.9 \\
Others & 2.0 & 0.8 & 0.8 & 2.7 & 0.7 & .06 \\
\hline Total $^{\text {a }}$ & 100.1 & 100.0 & 100.1 & 99.9 & 100.0 & 100.0 \\
\hline
\end{tabular}

Sources: Leete (1996) for 1957 to 1991 data; Saw (2007) for 2000 data; and Department of Statistics (2011) for 2010 data.

Note: a. Totals do not all add up to 100 due to rounding.

dian immigrants, and their descendants (Abdullah 1997). ${ }^{5}$ To partly assuage these fears, the British colonial authorities, together with the local political elites, ensured that the special position of the Malays and other indigenous people was enshrined in the proposed constitution for the new nation by designating Malay as the national language, Islam as the official religion, and a quota for Bumiputeras in public sector jobs and scholarships for higher education, among other items.

\section{The Electoral System and General Elections}

Malaysia has gone through thirteen general elections since independence. Table 2 provides a summary of the election results for all thirteen general elections. The last column measures the distortion effect, which is defined as the difference between the percentage share of seats that $\mathrm{BN}$ won and the percentage of popular votes it received. ${ }^{6}$ The Alliance/ $\mathrm{BN}$ benefited significantly from the distortion effect during the first eleven general elections. ${ }^{\text {? }}$

There were several reasons for this success. First, the rapid economic growth that Malaya, and later Malaysia, enjoyed during the first forty years of independence uplifted the livelihood of most Malaysians. In particular, universal education and health care were provided at very low cost to all citizens. Physical infrastructure improved tremendously. This track record of economic prosperity and the ensuing political and ethnic stability enabled BN to claim credit for this growth (Mutalib 2000).

Another reason for BN's success was the divisions among the opposition parties. From 1957 to 1998, the opposition was made up of fragmented individual parties choosing to go to the polls without any formal electoral pact (Ufen 2009). By operating as a multiethnic coali- 


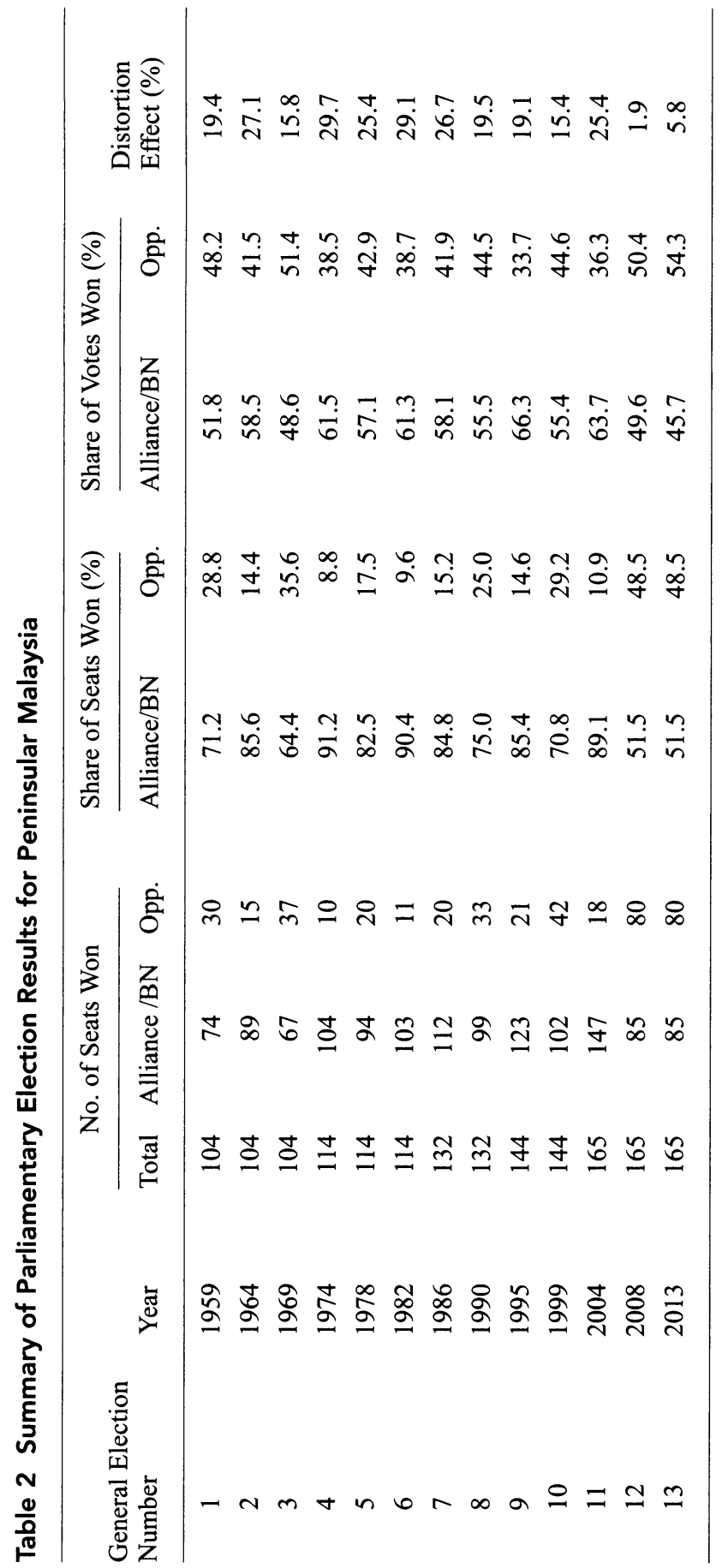


tion, Alliance/BN was able to occupy the middle ground in the ethnic spectrum and not portray itself to be an ethnic-based party. However, opposition politics in Peninsular Malaysia has been dominated by two ethnic-based parties: Parti Islam Se-Malaysia (PAS), an Islamist party drawing its support almost exclusively from the Malay-Muslim community, and the Democratic Action Party (DAP), which gets most of its support from the non-Malays. This fragmentation, together with the first-past-the-post system, enabled BN to win a large number of seats comfortably, even though its share of votes was between 50 and 65 percent for each of the first eleven elections. In fact, the distortion effect mentioned earlier was amplified mainly due to the ability of BN to hold the middle ground and win convincingly in ethnically mixed seats.

A third reason for BN's long string of victories was the increasing weightage given to rural and ethnically mixed constituencies over several delineation exercises ( $\operatorname{Lim} 2002)$. In Malaysia, the rural areas of the country are mostly populated by Malays. Over the years, there has been constant gerrymandering by the Election Commission (EC) (Lim 2002), which is tasked to delineate the apportioned constituencies based on Article 46 of the Malaysian Federal Constitution. The constitution, however, has left it to the EC to interpret and apply important but vague and undefined terms such as "a measure of weightage," "rural," and "urban" when delineating electoral constituencies. The EC's application of rural weightage has been a source of controversy as it takes precedence over the fundamental principle of equal size (Lim 2002).

However, the situation changed dramatically since the twelfth general election (GE12) held in 2008. BN's share of popular votes in Peninsular Malaysia, which has been more than 50 percent since 1974, has declined significantly in the last two general elections. A plausible reason for this shift was the emergence of a multiethnic opposition coalition that provided an alternative vision for the country's future that all communities could accept (Leong 2012). In GE12, the former deputy prime minister, Anwar Ibrahim, who had been expelled from the government and jailed in 1998, was able to forge an electoral pact between his newly formed party, Parti Keadilan Rakyat (PKR), and the two leading opposition parties (i.e., DAP and PAS) in the peninsula. This informal group then went on to produce a common election manifesto and campaigned jointly in many parts of the country. The election result was stunning. BN suffered a severe setback in terms of both the number of seats as well as the share of popular votes. More damaging, $\mathrm{BN}$ lost control of five of the eleven state governments in the peninsula. Among them were the 
most industrialized and urbanized states of Selangor, Penang, and Perak. $\mathrm{BN}$ was also routed in the federal territory of Kuala Lumpur, the commercial capital and largest city in Malaysia. However, within a year, the PR state government in Perak was toppled when three of its state assembly members crossed over to BN.

Following this somewhat unexpected success in 2008, the electoral pact was transformed into a coalition called the Pakatan Rakyat (PR) or People's Alliance, made up of Anwar Ibrahim's PKR, DAP, and PAS. During the past five years, PR's component parties have been able to attract a number of young leaders from the different ethnic groups in the country. State financial coffers have been substantially improved through good governance in the four PR-governed states of Kelantan, Kedah, Penang, and Selangor (Auditor General of Malaysia 2011a, 2011b) ${ }^{8}$ In the latter two states, there was a marked improvement in administrative efficiency in the state government machinery. In spite of the $\mathrm{BN}$ controlled federal government's continuous attempt to undermine this coalition (Liow and Pasuni 2010), PR has been able to maintain its unity up to the GE13, held in May 2013. While BN still had the advantage of using the extensive federal government machinery to help its election campaign, as well as had control over the mainstream media, the emergence of Internet-based news portals and blogs leveled the playing field to some extent (Gomez and Chang 2013; Pepinsky 2009; Rajaratnam 2009).

The election campaign was very intense, because for the first time in Malaysia's electoral history there was no assurance that BN would be able to retain its parliamentary majority. Ultimately, the results were disappointing to Pakatan Rakyat. As mentioned above, while there was no change in the number of seats won by both sides in Peninsular Malaysia, there was a shift in the voting pattern. In particular, BN made gains in some rural areas while it lost few urban seats.

\section{Ethnicity and Urbanization}

The foundations of participatory political systems arose from rapid industrialization. Weber (1978) argued that modern political upheaval can be traced back to economic changes and shifting populations. Nevertheless, Lerner (1964) hypothesized that a modernizing society needed to achieve a certain minimalist threshold of urbanization before a participant society can be seen to emerge. Urbanization also results in the growth of modern interest groups whose demands and opposition to political elites lead to expansion of political communities. In summary, rapid urbanization results in a decentralization of political power (Lipset 1959). 
Urbanism does not just involve growth of cities. It also leads to broader social transformation. Specifically, it leads to the mobilization of both the rural and urban electorate by politicians. Thompson (2013) argues that when there is a lack of an electoral process, rural identities and the cultural discrimination felt by people of rural origin may be a source of social unrest. A clear example of this is the prolonged political impasse ongoing in Thailand. However, when a proper electoral process is in place, a flourishing two-party system may develop. An early study by Cutright (1963) in the United States affirmed that increasing urbanization seems to be conducive for the development of a competitive party system. There have also been documented cases of changes in voting patterns due to urbanization in other developed countries such as Turkey (Shmuelevitz 1996) and Italy (Fried 1967).

Urbanization has also been linked to political instability. Given the large influx of migrants into urban areas, the lack of planning of amenities by urban authorities often leads to an expectation gap between the dream of city life and the harsh realities that these migrants face. This in turn causes relative deprivation and social-psychological maladjustment, which leads to political radicalization and support for protest movements where grievances are aired through demonstrations. Such scenarios are prevalent not only in Latin America (Cornelius 1969) but also in Africa as well. Resnick (2012) classifies this marginalized group as the urban poor and found that this group tends to be politically mobilized through the use of populist strategies by opposition parties in a number of African countries.

Compared to the literature on urbanization, there has been more research on the role of ethnicity in the determination of electoral outcomes. Ethnicity is a frequently used tool to galvanize political support. Its use is especially prevalent when there is a sudden democratic transition (Ottaway 1999). In such situations, voters may resort to voting along ethnic lines as they may feel likelier to receive greater benefits by voting for a politician of the same ethnicity, rather than for someone outside of the ethnic group (van de Walle 2007). This so-called cognitive shortcut is more prevalent among those with lower education attainment and as such it may be difficult for those individuals to distinguish the differences between political parties (Noris and Mattes 2003).

The question of whether ethnicity remains a significant factor in the urban context has been a subject of debate among political analysts. One school of thought maintains that urbanization actually leads to greater interethnic competition over scarce, but highly visible, resources and opportunities (Bates 1983; Melson and Wolpe 1970). 
Urbanization, however, could contribute to more cosmopolitan worldviews that may nullify the ethnicity effect (Lipset 1959; Parsons 1975). This could lead to what Thompson (2013) refers to as an "urban cosmopolitan chauvinism" bias whereby urbanites perceive themselves as far superior to their rural peers. Also, prolonged interaction with other ethnic groups increases awareness of commonly shared characteristics, whereas infrequent contact can reinforce hostile ethnic stereotyping (Allport 1979).

Prior studies (Feagin 1972; Mohd Fuad et al. 2011) have analyzed the effects of ethnicity and urbanization independently and researchers have tended to treat both factors as additive rather than interactive. In contrast, Whitby (1985) introduced an interaction term consisting of both these factors to analyze the voting patterns of politicians elected to the US Congress. He concluded that the interaction between urbanization and an increasing proportion of the black population led to more liberal voting behavior on legislation passed by the US Congress. Urbanization therefore conditions the effect of race.

To understand the role of ethnicity and urbanization in determining the electoral outcome in the context of a developing country, one has to examine the demographic development of Malaysia since its independence in 1957. During British colonial rule and immediately after independence, agriculture was the dominant sector of the economy. During that period, most urban centers in the country had large Chinese majorities. Given that most Malays were employed in the agricultural sector, they lived predominantly in rural areas. Since independence, Malaysia has seen rapid modernization and industrialization with manufacturing taking over from agriculture as the main contributor to the economy. Rapid industrialization gave impetus to the movement of population from rural villages to towns and cities. According to Yaakob, Masron, and Fujimaki (2012), Malaysia has experienced rapid growth in urbanization during the last five decades, but urbanization was more pronounced during the 1980s and 1990s. Levels of urbanization have grown from 28.4 percent in 1970 to 71 percent in 2010 (Department of Statistics 2011). Malays now form the majority in most urban centers in Peninsular Malaysia because of the rural-urban migration that has taken place (McGee 2011).

Following a racial riot that occurred after the 1969 general election, the government began the implementation of the New Economic Policy (NEP), a legislated affirmative action policy meant to rectify the economic imbalance between the Malays and the non-Malays (Chin 2001). The implementation of the NEP aided by rapid industrialization and eco- 
nomic development has resulted in the rise of a Malay middle class that is increasingly less dependent on affirmative action but more interested in universal issues like participatory democracy, justice, and human rights (Saravanamuttu 2001).

Middle-class Malays are now better educated, better informed, with better access to alternative media (Pepinsky 2009). They are now more economically independent and located in urban areas and are at ease with interethnic economic and social relationships (O'Shannassy 2009). They, together with their non-Malay counterparts, have been pressing the cause for democracy more fervently under a nascent multiracial platform (Liow 1999). This cohort opted for change and is located in urban areas (Welsh 2013). The rise of the middle-class Malays culminated in the significant loss of BN's two-thirds majority in the 2008 and 2013 elections, respectively, as seen in Table 2 above (Khoo 2013).

Several factors have also contributed to the rising discontent among Malaysians across racial divisions. These include rising crime, corruption scandals, weakness of the judicial system, and increasing cost of living in general (Moten 2009). Other studies using a sociological approach argue that economic growth and the pressures of materialism and urbanization have strengthened rationalism and weakened ethnic considerations in deciding whom to vote for (Mansor 1992, 1999).

Indeed, as a country moves into the middle-income range during economic transition, it leads to changes in the social structures, beliefs, and culture that foster democracy. Huntington (1991) refers to this as a "Third Wave" of democratization. The recent election results have also triggered debate of whether we have indeed seen the end of ethnic politics in Malaysia. It is without doubt that parties canvassing on a pure ethnic political platform have been severely weakened, but to say that ethnic politics have been totally extinguished in Malaysia would be premature (Arakaki 2009; Balasubramaniam 2006; Lian and Appudurai 2011; Moten 2009; Noh 2014; Pepinsky 2009).

Nevertheless, the uncoupling of ethnic interests from ethnic identity of their advocates is steadily progressing as exemplified by the actions undertaken by opposition parties in power at the state level. Politicians from both sides of the political divide are beginning to see the benefits of addressing sensitive or racially charged issues as an across-the-board responsibility (Mohamad 2008). This is evidenced in the last two elections with the emergence of a two-party coalition system with the charismatic Anwar Ibrahim leading a credible opposition coalition that has presented itself as an alternative to the ruling BN coalition (Mohamad 
2008; Moten 2009). The emergence of a two-party coalition system may be linked to the rapid urbanization of the country.

Thompson (2013), however, asserted that although the current discursive argument points to a sharp urban-rural divide between city and village dwellers, it ignores the fact that there is substantial movement between rural and urban voters. He points out that although PAS used the pervasive urban cosmopolitan chauvinism tactic in mobilizing the rural dwellers against its arch-enemy $\mathrm{BN}$, it has not been an outright success. In contrast to the Mahathir administration, which has been accused of neglecting rural development (Thompson 2013), the former prime minister Abdullah Badawi and the current prime minister Najib Razak have made the interests of rural Malaysia a key cornerstone in their policymaking decisions. They realize that there is much to lose if rural Malaysia continues to be ignored in the name of economic progress.

Increasing urbanization has affected the ethnic composition of urban areas in Malaysia. Thus, the question is, which of these two factors is leading to the changes in the electoral dynamics of Peninsular Malaysia? An econometric methodology to separate and quantify the marginal effect of the urbanization-ethnicity interaction is presented in the next section.

\section{Data and Methodology}

Data

The dependent variable in the model is defined as the proportion of votes won by $\mathrm{BN}$ in each of the 165 parliamentary constituencies considered in this study, calculated as the number of votes that $\mathrm{BN}$ garnered for a parliamentary constituency, divided by the total number of valid votes for that corresponding parliamentary constituency. These data were obtained from the electoral results published online by the Malaysian Election Commission. ${ }^{9}$

The explanatory variables in the model specification include (1) the total number of eligible voters from each of the four ethnic groups in each parliamentary constituency, classified as Bumiputera, Chinese, Indians, and Others; and (2) Area - the physical area of the parliamentary constituencies that is used as a continuous measure of urban development. The ethnic group classification of Bumiputera encompasses the Malays, Orang Asli (which refers to the aborigines of Peninsular Malaysia), Bumiputera Sabah, and Bumiputera Sarawak. 
Using The Star newspaper ${ }^{10}$ (April 21, 2013), which had obtained data from the Malaysian Election Commission on the percentage composition of the four ethnic groups in each of the 165 parliamentary constituencies, the total number of eligible voters from each of the four ethnic groups was computed by multiplying the respective ethnic percentage composition with the total number of eligible voters in that particular constituency. This study does not directly use the percentage composition of the four ethnic groups provided by The Star as the explanatory variables primarily because the use of such compositional explanatory variables (with a unit sum constraint) in a regression analysis, even for a linear regression model, may lead to biased and incorrect estimates, resulting in misleading inferences (Hron, Filzmoser, and Thompson 2012). ${ }^{11}$

Data on the physical area of the parliamentary constituencies were obtained from Greenberg and Pepinsky (2013), and have also been used by Ostwald (2013) in his analysis of the relationship between district size and voter density across the Malaysian parliamentary constituencies.

In addition to using Area as the continuous measure of urbanization, we also use data from Politweet that categorize the 165 parliamentary constituencies as either urban, semi-urban, or rural to aid our analysis. ${ }^{12}$ According to Politweet, a constituency is defined as rural if there are villages, small towns, or farmlands distributed within the constituency. Semi-urban constituencies are those that contain larger towns and/or numerous small towns as compared to a rural constituency, and may also contain small villages. Urban constituencies refer to cities where urban development occurs in a majority of the constituency. The Politweet classification was done based on Google Maps satellite imagery and the Election Commission of Malaysia maps. The three-step methodology in determining the level of urban development of a constituency can be found in Appendix 1. Based on this classification, the number of rural, semi-urban, and urban constituencies is eighty-one, forty-four, and forty, respectively.

By combining the data on the physical area of the constituencies with the Politweet urbanization classification, Figure 1 plots the areas of the 165 parliamentary constituencies in their respective urban development classification, with the areas ranging from 0.0005 to $0.66433 .{ }^{13}$

It can be seen from Figure 1 that urban constituencies are associated with smaller areas, while rural constituencies are associated with larger areas. In particular, the median areas for the rural, semi-urban, and urban constituencies are $0.060,0.037$, and 0.003 , respectively. Therefore, it is 
Figure 1 Areas of the 165 Parliamentary Constituencies in Their Respective Urban Development Classification

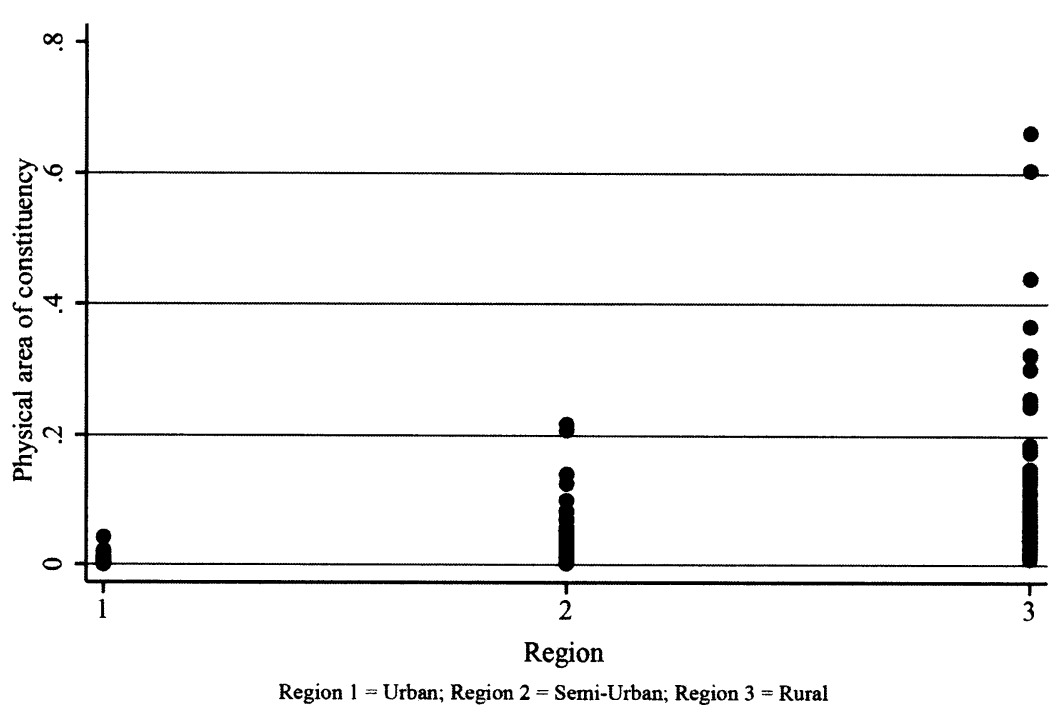

reasonable to conclude that parliamentary constituencies that are larger in physical size are also more rural in nature, while parliamentary constituencies that are smaller in physical size are more urban in nature. In other words, along the area continuum, constituencies with small areas refer to urban constituencies while constituencies with large areas refer to rural constituencies.

\section{Methodology}

The dependent variable, proportion of votes garnered by $\mathrm{BN}$, is a proportion quantity restricted to an interval of 0 and 1 (or referred to as a unit interval). Therefore, the model specification for a fractional dependent variable, $y_{i}$, as described by Papke and Wooldridge (1996), is assumed as follows:

$$
\begin{aligned}
& y_{i}=F\left(x_{i}{ }^{\prime} \beta\right)+u_{i} i=1,2, \ldots, n \\
& E\left(y_{i} \mid x_{i}\right)=F\left(x_{i}{ }^{\prime} \beta\right), i=1,2, \ldots, n
\end{aligned}
$$


where $x_{i}$ are the explanatory variables for the $i$ th observation and $F($.$) is$ typically chosen to be a known cumulative distribution function satisfying $0<F\left(x_{i}^{\prime} \beta\right)<1$ for all $x_{i}^{\prime} \beta \in R$, ensuring that the predicted values of $y$ will lie between the unit interval. The term $u_{i}$ is a random error term with a conditional mean of 0 . Equation 1a decomposes the observation into two components - the deterministic (or predictable) component given by $F\left(x_{i}^{\prime} \beta\right)$ and a random (or unpredictable) component given by $u_{i}$. Equation $1 \mathrm{~b}$ is derived by taking the conditional expectations of Equation $1 \mathrm{a}$, and it models the conditional expectation of $y_{i}$ (i.e., the average value of $y_{i}$ given a set of $x_{i}$ values) as a deterministic function given by $F\left(x_{i}^{\prime} \beta\right)$. It is the conditional expectation function in Equation $1 \mathrm{~b}$ that is estimated.

The vector of parameters in Equation 1a, $\beta$, is estimated using the Bernoulli quasi-maximum log-likelihood estimator (QMLLE), with the Bernoulli log-likelihood function given by

$$
l_{i}(\beta)=y_{i} \log \left[F\left(x_{i}^{\prime} \beta\right)\right]+\left(1-y_{i}\right) \log \left[1-F\left(x_{i}^{\prime} \beta\right)\right]
$$

The QMLLE of $\beta$ in this model is consistent and asymptotically normally distributed irrespective of the conditional distribution of $y_{i}$. In this article, $F($.) is chosen to be a logistic function that is strictly monotonic and defined as

$$
F(z) \equiv \frac{\exp (z)}{[1+\exp (z)]},
$$

where $z$ is defined as $x_{i}^{\prime} \beta$ from Equation 1a. The model specification in Equation 1a, coupled with this logistic function in Equation 3, is hence referred to as the fractional response logit model. ${ }^{14}$

The nonlinear model specification in Equation 1a is chosen over the linear specification because linear regression models are not appropriate for bounded values. Therefore, using the linear regression model will result in model misspecification with inefficient estimators, thus leading to incorrect inferences (Hron, Filzmoser, and Thompson 2012). Moreover, predicted values from a linear specification are not guaranteed to lie in the unit interval. Linear regression techniques also assume that the effect of any explanatory variable is constant throughout the range of values of the explanatory variable.

Further, by specifying the fractional response model in Equation 1a, no a priori assumption on the range of values that the dependent variable can take is made, except that it must be within the unit interval. ${ }^{15}$ In doing so, the model specified in Equation 1a accounts for all possibili- 
ties, including the possibility of a constituency observing a value of either 0 or 1 for the dependent variable. It should also be noted that the fractional response model is used not only when the dependent variable records extreme values of 0 or 1 , but that it has an added benefit of being able to deal with such values, avoiding the previous practice of ad hoc transformations.

\section{Model Specification}

Using Equation $1 \mathrm{~b}$, the expected proportion of votes garnered by $\mathrm{BN}$ is modeled as a function of the number of voters in each of the four different ethnic groups, and the area of the parliamentary constituencies that is used as a continuous measure of urban development. This model is further augmented by including interaction terms between the variables. The model is subsequently represented as such:

$$
E(y \mid x)=F\left(\begin{array}{c}
\beta_{0}+\beta_{1} \text { Bumiputera }+\beta_{2} \text { Chinese }+\beta_{3} \text { Indians }+\beta_{4} \text { Others }+ \\
\beta_{5} \text { Area }+\beta_{6} \text { Bumiputera. Area }+ \\
\beta_{7} \text { Chinese.Area }+\beta_{8} \text { Indians. Area }+\beta_{9} \text { Others. Area }
\end{array}\right)
$$

where Bumiputera, Chinese, Indians, and Others represent the number of voters (in 10,000s) from the respective ethnic groups of the parliamentary constituencies, and Area is the proxy to measure the level of urban development for the parliamentary constituencies.

The present study improves earlier studies (Feagin 1972; Mohd Fuad et al. 2011) by including the interaction effects of urbanization on ethnicity in determining the proportion of votes garnered by BN. The inclusion of interaction terms accounts for the synergy effect of both ethnicity and urbanization, thereby allowing for the complementary effect of urbanization on ethnicity to influence the proportion of votes garnered by BN. Moreover, Brambor, Clark, and Golder $(2006,64)$ note that when analyzing political studies, interaction terms should be included whenever the analysis involves a conditional hypothesis, defined as when "a relationship between two or more variables depends on the value of one or more other variables."

\section{Results}

\section{Estimation Results}

The model specified by Equation 4 is estimated by quasi-maximum likelihood methods and the results are presented in Table 3. 
Table 3 Fractional Response Logit Regression Results

\begin{tabular}{lc}
\hline Variable & Regression Results \\
\hline Bumiputera & -0.0014 \\
& $(0.0237)$ \\
Chinese & $-0.2279^{* * *}$ \\
& $(0.0284$ \\
Indians & 0.0034 \\
& $(0.0727)$ \\
Others & $-1.2622^{* * *}$ \\
& $(0.4859)$ \\
Area & -0.0789 \\
& $(1.0256)$ \\
Bumiputera x Area & 0.0107 \\
& $(0.2349)$ \\
Chinese x Area & $1.5269^{* *}$ \\
Indians x Area & $(0.6691)$ \\
& -1.3102 \\
Others x Area & $(1.3504)$ \\
Constant & 6.0453 \\
& $(3.9607)$ \\
& $0.3518^{* * *}$ \\
& $(0.1163)$
\end{tabular}

Notes: As discussed in the text, only the sign and not the magnitude of the coefficients presented in Table 3 can be interpreted. Standard errors are in parentheses. ${ }^{*} p \leq 0.10 ;{ }^{* *} p \leq 0.05$; ${ }^{* * *} p \leq 0.01$

Before interpreting the results, a few points are in order with regard to the coefficients. First, for a fractional response logit model, unlike linear regression models, $\beta_{j}$ alone does not represent the marginal effect of the explanatory variable $x_{j}$. Appendix 2 details how the marginal effects of an explanatory variable of interest can be computed. Second, the sign of the coefficient $\beta_{j}$ for this class of models indicates the direction of the marginal effects of the explanatory variable on the dependent variable. Taking the above two points together, only the signs of the coefficients in Table 3, and not the magnitudes, are interpretable.

For the purpose of this article, the discussion of results will be centered on the three main ethnic groups that are the most important in Peninsular Malaysia politics: the Bumiputera, Chinese, and Indians. Referring to Table 3, the results show that of the three main ethnic groups, only the Chinese ethnic group is a statistically significant variable, bear- 
ing a negative coefficient. Area was found to be statistically insignificant at the conventional level of significance. This result implies that the degree of urban development of a particular constituency, by itself, does not influence the level of support for the government. However, the positive and statistical significance of the interaction term between Area and Chinese reveals that there is a complementary effect between these two variables. The results imply that there is a significant extra effect of urbanization (as proxied by Area) on the Chinese voters to influence the proportion of votes garnered by $\mathrm{BN}$, ceteris paribus. More specifically, the positive coefficient of this interaction term implies that for every additional Chinese voter in a parliamentary constituency, ceteris paribus, the increase in the proportion of votes to $\mathrm{BN}$ is higher in larger (rural) parliamentary constituencies than smaller (urban) parliamentary constituencies. This positive effect negates the decrease in the proportion of votes to $\mathrm{BN}$ arising from the negative coefficient of Chinese.

However, the other ethnic group variables (Bumiputera and Indians), and their interaction with Area, are all statistically insignificant. This implies that an increase in either Bumiputera or Indian voters in a parliamentary constituency, ceteris paribus, will result in no change in the proportion of votes to BN. There is also no added effect that comes from the level of urbanization in that constituency. Therefore, it seems that the voting intentions of the Bumiputeras and Indians are constant irrespective of the level of urban development of the parliamentary constituency that they are in.

The results suggest that the Chinese-Urbanization factor is having the most dominant influence on the proportion of votes garnered by BN. The next subsection provides plots to visualize the underlying patterns in the ethnicity and urbanization effects on the proportion of votes to $\mathrm{BN}$. These plots provide interesting insights into understanding the underlying relation between these variables and reveal deviations from patterns that may not be detected easily.

\section{Ethnicity and Urbanization Effects}

Using the estimation results in Table 3, Figure 2 provides a visualization of the ethnicity and urbanization effects by plotting the marginal effects of the number of voters from each ethnic group on the predicted proportion of votes to $\mathrm{BN}$, across the range of areas of the parliamentary constituencies. Specifically, Figure 2 plots the change in the predicted proportion of votes to $\mathrm{BN}$ that arises from an increase in the number of voters from each respective ethnic group, for the range of areas of the parliamentary constituencies. The horizontal axis in Figure 2 represents 
Figure 2 Marginal Effects of Respective Ethnic Voter Numbers on the Predicted Proportion of Votes to BN, Across the Range of Constituency Areas

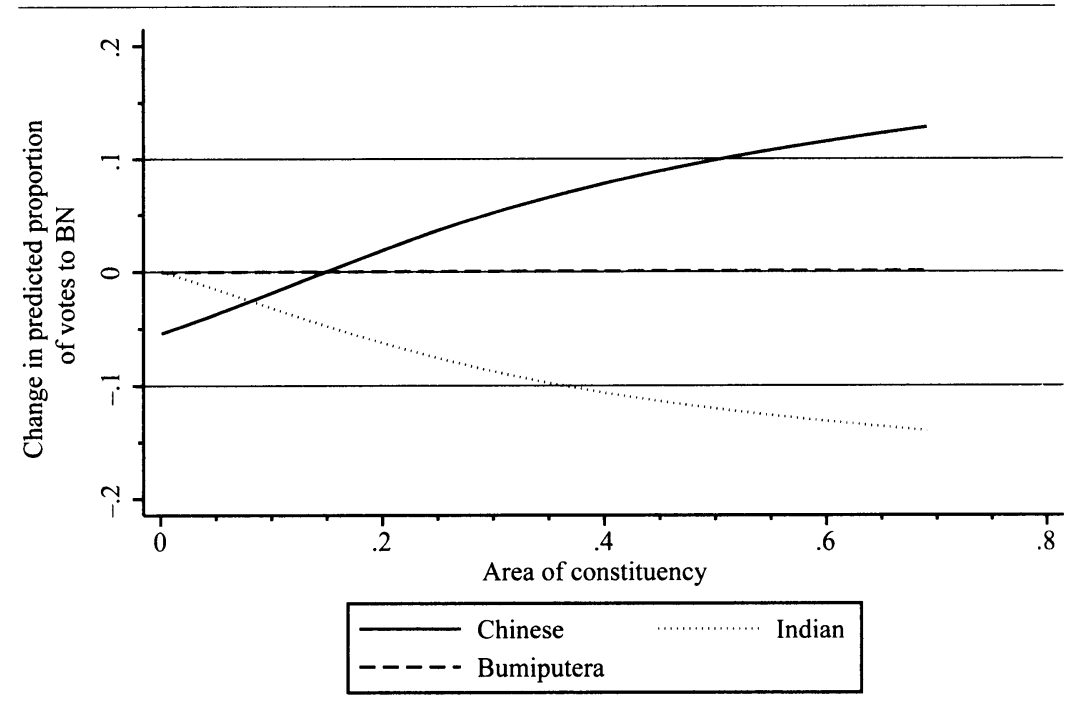

the range of areas of the 165 parliamentary constituencies and is used as a continuous measure of urban-rural development, where a constituency with a smaller area is associated with being an urban constituency and vice-versa. The vertical axis represents the change in the predicted proportion of votes to $\mathrm{BN}$ that arises from an increase in the number of voters from each of the ethnic groups.

Referring to Figure 2, it is evident that regardless of the area of the constituency, an increase in the number of Bumiputera voters in a constituency, ceteris paribus, results in no change in the predicted proportion of votes to $\mathrm{BN}$. Therefore, whether the constituency is an urban or rural region, an increase in the number of Bumiputera voters in that constituency, ceteris paribus, does not alter the level of support for the ruling coalition, BN.

Furthermore, the marginal effects of the Chinese voters are significantly larger than those of the Bumiputera voters. Given an increase in the number of Chinese voters relative to the other ethnic groups, the change in the predicted proportion of votes to $\mathrm{BN}$ is negative in smaller (urban) constituencies while this change is positive in larger (rural) con- 
stituencies. Although the support for $\mathrm{BN}$ is positive in large (rural) constituencies with a higher relative number of Chinese voters, this level of rural Chinese support dwindles with larger constituencies, as shown by the tapering of the solid line in Figure 2. This implies that the level of urban development of a constituency influences the level of Chinese support for BN.

The predicted change in proportion of votes to $\mathrm{BN}$ from an increase in the number of Indian voters, ceteris paribus, is negative for all areas of constituencies in Figure 2. However, these marginal effects are statistically insignificant from zero and therefore an increase in the relative number of Indian voters in either an urban or rural constituency will not influence the level of support for BN.

\section{Ethnicity and Urbanization Effects: An Extended Analysis} Using the Categorical Measure of Urban Development The earlier analysis used area of constituencies as the continuous measure of urban development and subsequently plotted marginal effect graphs to illustrate the ethnicity and urbanization effects on the proportion of votes to BN. To extend and complement the former analysis, we also show the ethnicity and urbanization effects on the proportion of votes to $\mathrm{BN}$ by using the categorical measure of urban development where, as discussed earlier, the parliamentary constituencies are classified as urban, semi-urban, or rural. Specifically, for each ethnic group, we plot and observe the predicted proportion of votes to BN in urban, semiurban, and rural constituencies, over the range of number of voters from that ethnic group. To do this, we substitute, in turn, the median areas representing each of the region classifications $(0.003$ for urban, 0.037 for semi-urban, and 0.060 for rural) into Equation $1 \mathrm{~b}$ and obtain the predicted proportion of votes to $\mathrm{BN}$ for the range of voter numbers in each ethnic group. Figures 3-5 subsequently display the results.

In Figure 3, the predicted vote share for $\mathrm{BN}$ across the three region classifications declines very slightly throughout the range of Bumiputera voter numbers. Therefore, since an increase in the number of Bumiputera voters, ceteris paribus, changes the predicted proportion of votes to $\mathrm{BN}$ only marginally in either an urban, semi-urban, or rural constituency, it can be inferred that for the Bumiputeras, ethnicity has little influence on the level of support for BN. It is notable that in all three constituency types, the Bumiputera predicted vote to $\mathrm{BN}$ is less than 50 percent. However, it is evident from Figure 3 that it is the level of urban development that influences the level of support for $\mathrm{BN}$ among the $\mathrm{Bu}$ - 
Figure 3 Predicted Vote Share for BN in Urban, Semi-Urban, and Rural Constituencies for Varying Numbers of Bumiputera Voters

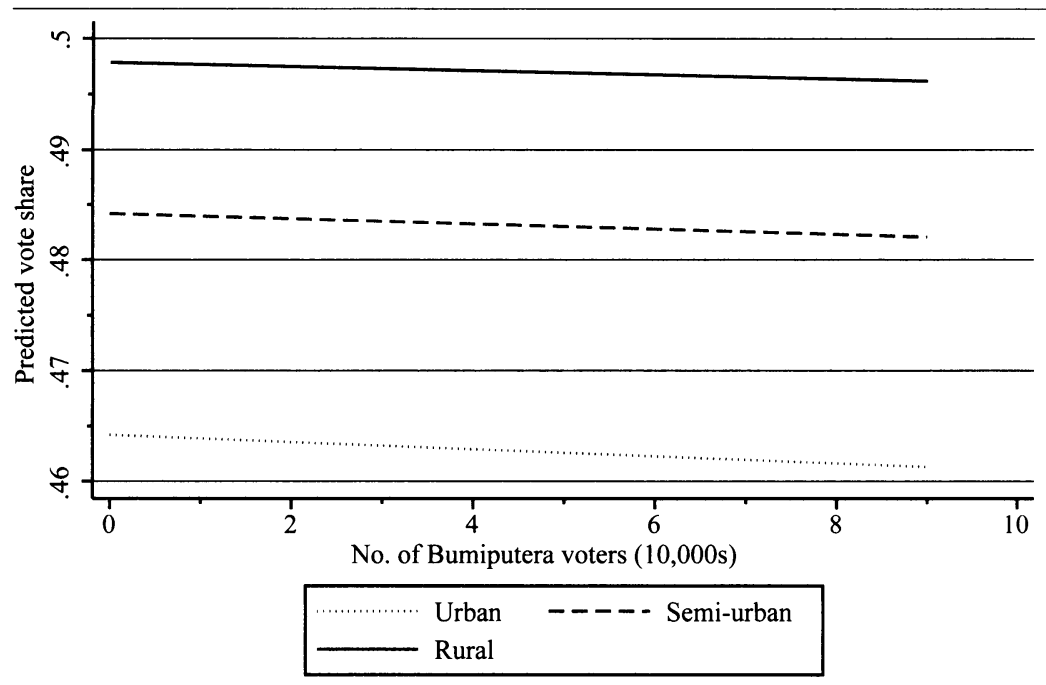

Figure 4 Predicted Vote Share for BN in Urban, Semi-Urban, and Rural Constituencies for Varying Numbers of Chinese Voters

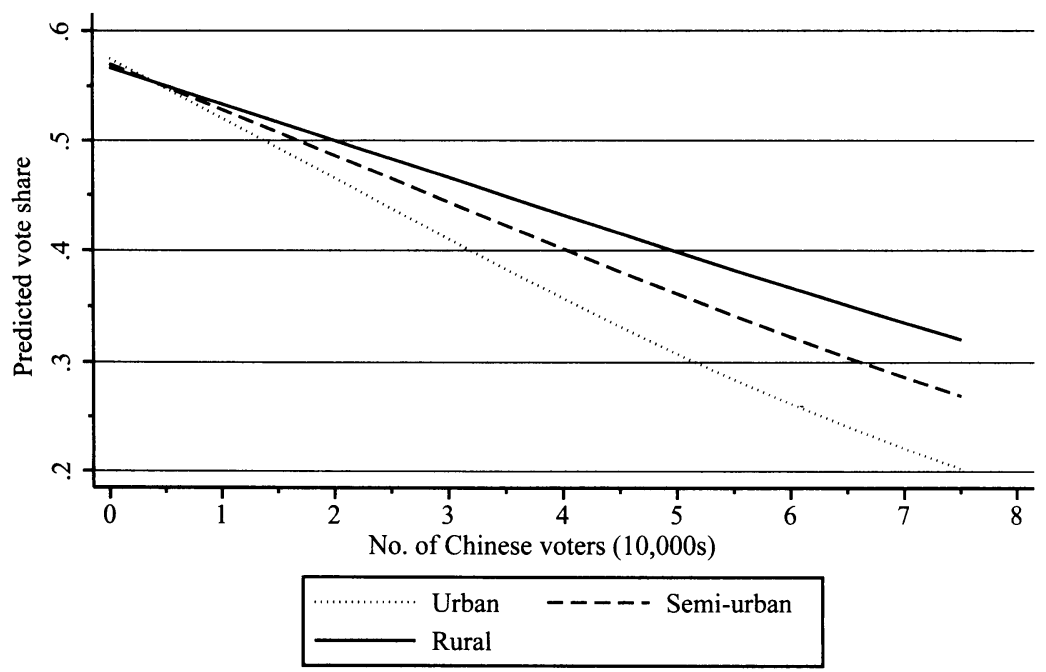


miputeras. Regardless of the number of Bumiputera voters in a given constituency, the model predicts that the proportion of votes to $\mathrm{BN}$ will be the lowest in an urban constituency, and it will be the highest in a rural constituency.

Figure 4 plots the predicted vote share to $\mathrm{BN}$ across the three region classifications over the range of Chinese voter numbers, revealing the presence of both ethnicity and urbanization effects. At small Chinese voter numbers (around 5,000) in a given constituency, the predicted proportion of Chinese votes to $\mathrm{BN}$ is approximately 55 percent, regardless of whether the constituency is urban, semi-urban, or rural. However, the negative trend lines for all three region classifications show that the level of support for $\mathrm{BN}$ decreases quite rapidly as the number of Chinese voters increases, thus capturing the ethnicity effect. This ethnicity effect is further fueled by the urbanization factor, as seen by the divergence in the predicted proportion of votes to $\mathrm{BN}$ across the three region classifications, with urban constituencies reflecting a sharper drop in the proportion of votes as compared to rural constituencies. In particular, for the same increase in the number of Chinese voters from 5,000 to 75,000, the predicted proportion of votes to $\mathrm{BN}$ in an urban constituency drops from 55 percent to approximately 20 percent, as compared to the drop to approximately 33 percent for a rural constituency.

In contrast to the divergent trend lines in Figure 4 for the Chinese voters, Figure 5 shows the trend lines across the three region classifications for the Indian voters converging. In a constituency with a low number of Indian voters, the predicted proportion of votes to $\mathrm{BN}$ is the highest if it is a rural district, and is the lowest if it is an urban district. This disparity in the vote share to $\mathrm{BN}$ across the three region classifications diminishes in constituencies with a higher number of Indian voters, with the predicted vote share to $\mathrm{BN}$ decreasing for both the rural and semiurban constituencies. The predicted vote share to $\mathrm{BN}$ for an urban constituency, however, remains constant over the range of Indian voters. It is also noted that for constituencies with fewer than approximately 25,000 Indian voters, the predicted proportion of votes to BN is the lowest in urban areas, reflecting the urbanization effect on the support for $\mathrm{BN}$.

However, the findings from Figure 5 for Indian voters should be treated with some caution. In most constituencies, the Indian share of votes is relatively small. The Kota Raja parliamentary constituency has the highest number of Indian voters with a 29.5 percent share. Another nine parliamentary constituencies have 20-24 percent of Indian voters, while in fifteen other parliamentary constituencies, they form 10-20 per- 
Figure 5 Predicted Vote Share for BN in Urban, Semi-Urban, and Rural Constituencies for Varying Numbers of Indian Voters

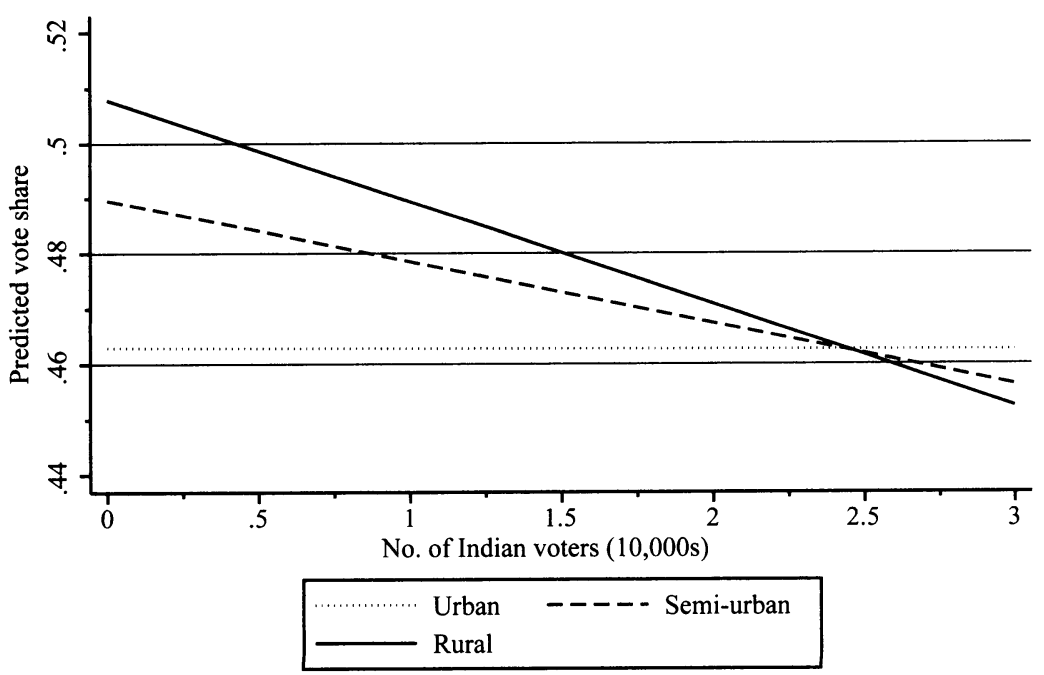

cent of the voters. Thus out of 165 parliamentary seats in Peninsular Malaysia, Indian vote share exceeds 10 percent only in twenty-five parliamentary seats, thus reducing their impact on the electoral outcome in most parliamentary seats.

A few additional points are also observed from Figures 3, 4, and 5. First, across all the ethnic groups, the support for $\mathrm{BN}$ is always the lowest in urban constituencies and the highest in rural constituencies. This is a clear indication that the level of urban development influences the level of support for BN, with more urbanized constituencies being proopposition. Second, as shown in Figure 3, the Bumiputera vote is evenly split with a slim majority for the opposition Pakatan Rakyat. In the aggregate, Bumiputera support for BN ranges from 46 percent in urban areas to 49 percent in rural areas. Third, the ethnic effect is the strongest among the Chinese, with support for BN declining sharply in constituencies that have a larger number of Chinese voters relative to the other ethnic groups.

\section{Discussion}

GE13 was arguably the most closely contested election in Malaysian history. In terms of popular votes, GE13 was the worst outcome for the rul- 
ing coalition in BN's history. For Malaysia as a whole, PR obtained more votes than BN. In Peninsular Malaysia, BN obtained only 45.7 percent of the votes cast, while PR obtained more than 54 percent of the votes. It is also intriguing to note from Figure 3 that even among Bumiputera voters, $\mathrm{BN}$ was unable to obtain majority support. Among the nonBumiputera, a clear majority voted for PR. Yet, BN won eighty-five seats to PR's eighty seats. A large proportion of BN's electoral success, however, can be attributed to victories in rural parliamentary seats as classified by Politweet. Of the eighty-five seats BN won in Peninsular Malaysia, sixty-six were classified as rural.

The key to understanding this outcome is to examine Chinese voter behavior in constituencies where their numbers are small. As can be seen from Figure 4, when the Chinese voters make up a small number in absolute terms in urban, semi-urban, and rural constituencies, their support for $\mathrm{BN}$ is more than 50 percent. The higher than 50 percent support for BN by Chinese voters appears to offset the slightly less than 50 percent Malay support for $\mathrm{BN}$ in rural areas, thus helping $\mathrm{BN}$ over the finish line in rural parliamentary constituencies. So, ironically, given that most of BN's eighty-five electoral seats are from the rural constituencies, BN's victory in the thirteenth general election can be partly attributed to the support of Chinese voters, and to a lesser extent, Indian voters, in constituencies where they are small in number. BN won sixty-one of the sixty-six rural seats where Chinese voters numbered 20,000 or fewer. This rural effect is further amplified by the malapportionment of voters between rural and urban constituencies. The variance between rural and urban seats has been increasing over several rounds of electoral delineations ( $\operatorname{Lim} 2002$; Ostwald 2013).

It is not clear why the Chinese support for $\mathrm{BN}$ increases when their numbers decrease in electoral constituencies (see Figure 4). One possible explanation is that where Chinese voters make up a small percentage of the electorate, they may tend to feel less secure. As their numbers increase, they may lose their sense of insecurity, and thus their support for $\mathrm{BN}$ declines sharply to as much as only 20 percent, especially for urban seats. Second, in rural constituencies, the role of government development spending has a bigger impact on the economic well-being of voters. This may influence their preference for BN among Chinese voters in rural areas. The motivation for the change in Chinese voter behavior as their numbers change needs to be explored in greater depth.

What are the implications of these findings for BN and PR? As the country transitions from a developing nation to a developed nation, Malaysia will become increasingly urbanized. Rural and semi-urban areas will become increasingly more urban in character as development 
moves beyond urban areas. This may result in BN's vote share decreasing across all ethnic groups. It is also compounded by the fact that younger voters tend to read news on the alternate media over which the $\mathrm{BN}$ government has very little control. Future delineations that skew rural-urban constituency sizes are becoming more difficult due to a more aware electorate. ${ }^{16}$ Thus, $\mathrm{BN}$ has to adopt a strategy that accounts for these factors.

$\mathrm{BN}$ has to refocus on urban areas for success in future elections. BN needs to reach out to urbanites of all ethnic groups and not treat urban seats as a lost cause. Less practice of divisive politics would be one step in the right direction. They should also woo both the Malay and the nonMalay votes in rural and semi-urban areas where they have some advantage in these areas. This should be especially targeted toward the Chinese voters since their voting patterns in rural and semi-urban areas play a decisive role.

Pakatan Rakyat has a clear decisive advantage in urban parliamentary seats. Support from all ethnic groups is above 50 percent. Urban parliamentary seats are therefore the easiest for PR to retain with popular support. Therefore, the strategy PR should employ to maintain urban support would be the provision of good governance, especially efficient municipal services in states where PR is the ruling coalition (Penang, Selangor, and Kelantan). This will ensure that there will be no swing back to BN in the coming general election. Contrary to BN's less than decisive advantage in rural and semi-urban seats, PR has opportunities to make inroads in these two seat classifications. Early identification of candidates for each rural and semi-urban constituency is imperative and it would be especially advantageous if the identified candidates were local politicians. Early identification of candidates would reduce political bickering among would-be aspirants and allow identified candidates to work in their respective constituencies in building up their support base.

\section{Conclusion}

More recently, the debate of ethnicity's having an effect on voter sentiment has attracted considerable interest in a multiethnic society such as Malaysia. However, the findings in this article suggest that there is more to it than ethnic undertones. This article has made two contributions. First, although the results of Malaysia's GE13 displayed an ethnic effect, the rapid urbanization of the country has also played a role in determining the outcome of the elections. Malaysians across ethnic lines voted overwhelmingly for PR in urban areas, whereas support for BN remains 
reasonably strong in rural areas. This article also sheds new light on the long-standing explanation that BN's continued dominance in Malaysian general elections is due to the solid rural Bumiputera vote. Our analyses have shown that non-Bumiputera votes in rural and semi-urban areas were the key to BN's holding on to power despite having slightly less than 50 percent support from Bumiputera voters, even in rural constituencies. However, reliance on the non-Bumiputera voter group is highly precarious due to the shrinking number of Chinese voters in rural areas. This is caused by rural-urban migration and the decline in birthrates among the Chinese population (Department of Statistics 2012).

Second, the fact that Malaysia is becoming increasingly urbanized also needs to be taken into account. Political parties from both sides of the political divide need to take heed of this development. As the country develops further toward becoming a high income nation, voting patterns for race-based parties may decline significantly. Instead, political parties that can identify with the rising demands of voters on bread and butter issues like the increasing cost of living, social justice, corruption, and basic human rights may gain the upper hand in future general elections.

A cautionary remark, however, is in order where the main point of contention would lie in the categorization of seats into urban, semi-urban, and rural constituencies done by Politweet. They have acknowledged that a better method can be used for the categorization of parliamentary constituencies through a gridding process (Balk et al. 2006). This study looked at the impact of urbanization and ethnicity on electoral support at the parliamentary level in aggregate. Local micro-factors that may have influences on the results of individual seats were not considered in our analysis. Therefore, future studies may look at the impact of urbanization and ethnicity at the state legislative level, which may provide further insight to the results obtained at the federal level.

Jason Wei Jian $\mathrm{Ng}$ is lecturer with the Department of Econometrics and Business Statistics at Monash University Malaysia and can be contacted at jason.ng.wj @ monash.edu. He received his $\mathrm{PhD}$ in econometrics from Monash University Australia. He is an early career researcher whose research focuses on applied econometrics in a wide range of policy issues such as financial development and economic growth, subjective well-being, and residential house pricing.

Gary John Rangel is lecturer of finance at Monash University Malaysia and can be contacted at gary.rangel@monash.edu. He received his $\mathrm{PhD}$ in finance from University Science Malaysia. His research focuses on behavioral finance, real estate, risk perception, and Malaysian politics and his work has appeared in International Finance Review and International Journal of Banking and Finance. 
Santha Vaithilingam is associate professor at Monash University Malaysia and is head of the Econometrics and Business Statistics Department. She can be contacted at santha.vaithilingam@monash.edu. Her research interests are in computable general equilibrium (CGE), financial econometrics, and behavioral economics. More recently, her work has been focused on modeling human behavior pertaining to technology adoption using advanced econometric techniques.

Subramaniam S. Pillay is associate professor of business and finance at Taylor's University, Malaysia, and can be contacted at subramaniam.pillay@taylors.edu.my. He received his $\mathrm{PhD}$ in policy analysis from the University of British Columbia. His research focuses on economic and currency crisis, and politics in Southeast Asia.

\section{Appendix 1}

The following three-step methodology was employed by Politweet in identifying the level of urban development of the parliamentary constituencies.

1. Locate the constituency on Google Maps (and Bing Maps, when the image was not clear).

2. Identify the area covered by urban development, and the degree of development.

3. Define the seat as either rural, semi-urban, or urban based on the definitions of the classifications described in the text.

\section{Appendix 2}

Using the general model specification in Equation 1, the marginal effect of an explanatory variable of interest, $x_{j}$, on the conditional mean $E(y \mid x)$ is given as

$$
\frac{\partial E(y \mid \boldsymbol{x})}{\partial x_{j}}=f\left(\boldsymbol{x}_{i}^{\prime} \boldsymbol{\beta}\right) \cdot \beta_{j}
$$

where $f\left(x_{i}^{\prime} \beta\right)$ is the derivative of the cumulative logistic distribution function defined as

$$
f(z) \equiv \frac{d F(z)}{d z}=\frac{\exp (z)}{[1+\exp (z)]^{2}}
$$

and $\beta_{j}$ is the coefficient attached to the $j$ th explanatory variable. Therefore, to compute the value of the marginal effect of $x_{j}$ on the conditional expected value of $y$ using Equation A2.1, appropriate values of all the explanatory variables, such as the mean or median value of the explanatory variables, need to be substituted into the function $f\left(x_{i}^{\prime} \beta\right)$ before multiplying it with $\beta_{j}$. 


\section{Notes}

The authors would like to thank Kai Ostwald for facilitating the acquisition of the data on the areas of the electoral districts; Tom Pepinsky for providing the details behind the calculation of these areas; Peter Filzmoser for his assistance pertaining to our queries on the isometric log-ratio transformation; Mahendhiran Nair for his comments on this article; and the editor and the two referees for their constructive feedback in the reviewing process of this article.

1. From 1957 until 1973, the coalition was known as the Alliance Party and was made up of three parties - the United Malays National Organisation (UMNO), the Malaysian Chinese Association (MCA), and Malaysian Indian Congress (MIC) - representing the three major ethnic groups in Peninsular Malaysia (or Malaya, as it was then known). Its name was changed to National Front or Barisan Nasional in 1971 after it expanded to become a thirteenmember coalition encompassing political parties from the Borneo states of Sabah and Sarawak, as well as those from Peninsular Malaysia.

2. The terms constituency and seat are used interchangeably.

3. In addition to the thirteen states, there are three federal territories that are directly administered by the central government: Kuala Lumpur, the main commercial center of the country; Putrajaya, the administrative capital; and Labuan Island off the coast of Sabah.

4. In Peninsular Malaysia, Malays form nearly 98 percent of the Bumiputera population; so for all intents and purposes, Bumiputera and Malay can be used interchangeably.

5. These fears did not abate with the granting of independence by the British. Singapore's founding prime minister Mr. Lee Kuan Yew in his official autobiography (Lee 1998) indicated this fear still persisted during the formation of Malaysia in 1963. There was fear that the inclusion of Singapore in Malaysia would "swamp the Malays" (Lee 1998, 363).

6. If we include Sabah and Sarawak, BN's advantage is even bigger as the rural overweightage is more pronounced in those two states.

7. The distortion effect calculation is based on Brown (2005).

8. Penang recorded a budget surplus of RM138 million in 2011, an increase of 312 percent compared to RM 33 million in 2010 when there was a 95 percent reduction in debt. Selangor also recorded an increase in revenue from RM1.57 billion in 2010 to RM1.634 billion in 2011 (Auditor General of Malaysia 2011a, 2011b).

9. The results of the thirteenth general elections for each partiamentary seat can be obtained from the Malaysian Election Commission website (http://result pru13.spr.gov.my/module/keputusan/paparan/paparan_Laporan.php\#).

10. The Star is a daily newspaper owned by MCA, a component party of $\mathrm{BN}$.

11. In particular, compositional data do not follow the usual Euclidean geometry where most statistical methods rely on it. Therefore, Hron, Filzmoser, and Thompson (2012) recommend transforming compositional variables to the Euclidean geometry via an isometric log-ratio transformation. The interested reader can refer to that paper for further details. In this study, we do 
not attempt to use the isometric transformed variables because (1) there are interpretability issues (even in a linear regression setting) and (2) there is currently no research on how to estimate regressions with interaction variables that contain both compositional and noncompositional variables, as will be shown later in our model specification.

12. Politweet is a nonpartisan research firm that has been monitoring Malaysian politics and activism on Twitter since 2009, and on Facebook since late 2012. See http://politweet.wordpress.com/2013/05/21/the-rural-urban -divide-in-malaysias-general-election/.

13. The area figures do not contain any units of measurement. According to Pepinsky, the physical areas of the electoral districts were created from the Geographic Information Systems (GIS) maps and were subsequently imported into $\mathrm{R}$ whereby the "maptools" library was used to calculate the area of each polygon representing an electoral district. The procedure in $\mathrm{R}$ does not return any unit of measurement. Nevertheless, a larger number represents a larger physical area of a constituency.

14. Using either the probit or logit model is an alternative strategy, but it involves transforming the dependent variable into a binary form, and will not provide meaningful results in quantifying the ethnicity and urbanization effects on BN's electoral performance.

15. Based on the data collected, the range of the dependent variable (proportion of votes garnered by $\mathrm{BN}$ ) is between 0.13 and 0.84 . Therefore, one could argue that given that the dependent variable does not lie near the unit interval bounds, a linear regression could suffice. However, doing so will be making an a priori assumption that the range of values the dependent variable can take is a subset of the unit interval.

16. An increasingly aware electorate has culminated into nongovernmental organizations (NGOs) seeking to pressure the Election Commission to ensure a clean and fair electoral process in Malaysia. The most well-known NGO is the Coalition for Clean and Fair Elections, popularly known as BERSIH. It has held mass rallies in 2007, 2011, and 2013, demanding reform of the postal balloting system, free and fair access to mass media for all parties, cleaning up of the electoral roll, elimination of dirty money politics, as well as elimination of corruption.

\section{References}

Abdullah, Firdaus Hj. 1997. "Affirmative Action Policy in Malaysia: To Restructure Society, to Eradicate Poverty." Ethnic Studies Report 15, 2: 189-221.

Allport, Gordon W. 1979. The Nature of Prejudice. 25th anniversary ed. Reading, MA: Addison-Wesley Publishing Company.

Arakaki, Robert K. 2009. "2008 Malaysian Election: The End of Malaysia's Ethnic Nationalism?" Asian Politics and Policy 1, 1: 79-96.

Auditor General of Malaysia. 2011a. "Auditor General's Report 2011 on the Penang State Government Financial Statement and the Financial Management of the State Department and Agencies.” Kuala Lumpur, Malaysia: National Audit Department. 
2011b. "Auditor General's Report 2011 on the Selangor State Government Financial Statement and the Financial Management of the State Department and Agencies." Kuala Lumpur, Malaysia: National Audit Department.

Balasubramaniam, Vejai. 2006. "Embedding Ethnic Politics in Malaysia: Economic Growth, Its Ramifications and Political Popularity." Asian Journal of Political Science 14, 1: 23-39.

Balk, D. L., U. Deichmann, G. Yetman, F. Pozzi, S. I. Hay, and A. Nelson. 2006. "Determining Global Population Distribution: Methods, Applications and Data." In Advances in Parasitology, ed. Alastair Graham, Simon I. Hay, and David J. Rogers, 119-156. Amsterdam, Holland: Academic Press.

Bates, Robert H. 1983. "Modernization, Ethnic Competition and the Rationality of Politics in Contemporary Africa." In State Versus Ethnic Claims: African Policy Dilemmas, ed. Donald Rothchild and Victor A. Olorunsola, 152-171. Boulder, CO: Westview.

Boo, Su Lyn. 2013. "GE13 an Urban, Not Chinese Swing, Says Analysts." The Malaysian Insider. www.themalaysianinsider.com/malaysia/article/ge13 -an-urban-not-chinese-swing-say-analysts (accessed October 10, 2013).

Brambor, Thomas, William Roberts Clark, and Matt Golder. 2006. "Understanding Interaction Models: Improving Empirical Analyses." Political Analysis 14, 1: 63-82.

Brown, Graham K. 2005. "Playing the (Non)Ethnic Card: The Electoral System and Ethnic Voting Patterns in Malaysia." Ethnopolitics 4, 4: 429-445.

Chin, James. 2001. "Malaysian Chinese Politics in the 21st Century: Fear, Service and Marginalisation." Asian Journal of Political Science 9, 2: 78-94.

Cornelius, Wayne A., Jr. 1969. "Urbanization as an Agent in Latin American Political Instability: The Case of Mexico." The American Political Science Review 63, 3: 833-857.

Cutright, Phillips. 1963. "Urbanization and Competitive Party Politics." The Journal of Politics 25, 3: 552-564.

Department of Statistics (DOS). 2011. "Population and Housing Census of Malaysia." Kuala Lumpur, Malaysia: Department of Statistics.

—_. 2012. "Population Projections, Malaysia 2010-2040." Kuala Lumpur, Malaysia: Department of Statistics.

Feagin, Joe R. 1972. "Civil Rights Voting by Southern Congressmen." The Journal of Politics 34, 2: 484-499.

Fried, Robert C. 1967. "Urbanization and Italian Politics." The Journal of Politics 29, 3: 505-534.

Gomez, James, and Han Leong Chang. 2013. "New Media and General Elections: Online Citizen Journalism in Malaysia and Singapore." In Democracy, Media, and Law in Malaysia and Singapore: A Space for Speech, ed. Andrew T. Kenyon, Tim Majoribanks, and Amanda Whiting. Abingdon, UK: Routledge.

Greenberg, Sarah, and Thomas B. Pepinsky. 2013. "Data and Maps for the 2013 Malaysian General Elections." Department of Government Working Paper. Ithaca, NY: Cornell University. 
Hron, K., P. Filzmoser, and K. Thompson. 2012. "Linear Regression with Compositional Explanatory Variables." Journal of Applied Statistics 39, 5: 1115-1128.

Huntington, Samuel P. 1991. The Third Wave: Democratization in the Late Twentieth Century. The Julian J. Rothbaum Distinguished Lecture Series. Norman: University of Oklahoma Press.

Khoo, Boo Teik. 2013. "The 13th General Elections (GE13) in Peninsular Malaysia: An Analysis of Issues, Outcomes, and Implications." In 13th General Election in Malaysia: Issues, Outcomes, and Implications, ed. Boo Teik Khoo. Chiba-shi, Japan: Institute of Developing Economies.

Lee, Kuan Yew. 1998. The Singapore Story: Memoirs of Lee Kuan Yew. Singapore: Marshall Cavendish Editions.

Leete, Richard. 1996. Malaysia's Demographic Transition: Rapid Development, Culture, and Politics. Kuala Lumpur: Oxford University Press.

Leong, Keith Yu Keen. 2012. The Future of Pakatan Raykat: Lessons from Selangor. Kuala Lumpur: Institute for Democracy and Economic Affairs.

Lerner, Daniel. 1964. The Passing of Traditional Society: Modernizing the Middle East. London: The Free Press of Glencoe.

Lian, Kwen Fee, and Jayanath Appudurai. 2011. "Race, Class and Politics in Peninsular Malaysia: The General Election of 2008." Asian Studies Review 35, 1: 63-82.

Lim, Hong Hai. 2002. "Electoral Politics in Malaysia: 'Managing' Elections in a Plural Society." In Electoral Politics in Southeast and East Asia, ed. Aurel Croissant and Marei John. Singapore: Friedrich-Ebert-Stiftung, Office for Regional Co-operation in Southeast Asia.

Liow, Joseph. 1999. "Crisis, Choice and Change: Malaysian Electoral Politics at the End of the 20th Century." Asian Journal of Political Science 7, 2: 45-74.

Liow, Joseph, and Afif Pasuni. 2010. "Debating the Conduct and Nature of Malaysian Politics: Communalism and New Media Post-March 2008." Journal of Current Southeast Asian Affairs 4, 4: 39-65.

Lipset, Seymour M. 1959. "Some Social Requisites of Democracy: Economic Development and Political Legitimacy." The American Political Science Review 53, 1: 69-105.

Mansor, Mohd Noor. 1992. "The Determinants of a Malay Ethnic Alignment." $\mathrm{PhD}$ diss., University of Bristol.

- 1999. "Crossing Ethnic Borders in Malaysia: Measuring the Fluidity of Ethnic Identity and Group Formation." Akademika 55, 1: 61-82.

McGee, Terry. 2011. "The Urbanisation Transition in Malaysia in the TwentyFirst Century." Akademika 81, 2: 109-121.

Melson, Robert, and Howard Wolpe. 1970. "Modernization and the Politics of Communalism: A Theoretical Perspective." American Political Science Review 64, 4: 1112-1130.

Mohamad, Maznah. 2008. "Malaysia-Democracy and the End of Ethnic Politics?" Australian Journal of International Affairs 62, 4: 441-459. 
Mohd Fuad, M. J., A. B. Junaidi, A. Buang, S. Selvadurai, A. C. Er, and N. Lyndon. 2011. "Ethnic Attitudes, Political Preferences, and the Politics of Stability." World Applied Sciences Journal 13 (Special Issue on Human Dimensions of Development): 34-38.

Moten, Abdul Rashid. 2009. "2004 and 2008 General Elections in Malaysia: Towards a Multicultural, Bi-Party Political System?" Asian Journal of Political Science 17, 2: 173-194.

Mutalib, Hussin. 2000. "Malaysia's 1999 General Election: Signposts to Future Politics." Asian Journal of Political Science 8, 1: 65-89.

Noh, Abdillah. 2014. "Malaysia 13th General Election: A Short Note on Malaysia's Continuing Battle with Ethnic Politics." Electoral Studies 34: 266-269.

Noor, Farish A. 2013. "The 13th Malaysian General Elections from a Sabah Perspective." The Round Table 102, 6: 541-548.

Noris, Pippa, and Robert Mattes. 2003. "Does Ethnicity Determine Support for the Governing Party? The Structural and Attitudinal Basis of Partisan Identification in 12 African Nations." Kennedy School of Government Research Working Papers Series. Cambridge: Harvard University.

O’Shannassy, Michael. 2009. "Beyond the Barisan Nasional? A Gramscian Perspective of the 2008 Malaysian General Election." Contemporary Southeast Asia 31, 1: 88-109.

Ostwald, Kai. 2013. "How to Win a Lost Election: Malapportionment and Malaysia's 2013 General Election." The Round Table 102, 6: 521-532.

Ottaway, Marina. 1999. "Ethnic Politics in Africa: Change and Continuity." In State, Conflict, and Democracy in Africa, ed. Richard Joseph, 299-318. Boulder, CO: Lynne Rienner.

Papke, Leslie E., and Jeffrey M. Wooldridge. 1996. "Econometric Methods for Fractional Response Variables with an Application to 401(k) Plan Participation Rates." Journal of Applied Econometrics 11, 6: 619-632.

Parsons, Talcott. 1975. "Some Theoretical Considerations on the Nature and Trends of Change of Ethnicity." In Ethnicity, Theory and Experience, ed. Nathan Glazer and Daniel Patrick Moynihan, 53-83. Cambridge: Harvard University Press.

Pepinsky, Thomas B. 2009. "The 2008 Malaysian Elections: An End to Ethnic Politics?" Journal of East Asian Studies 9, 1: 87-120.

Rajaratnam, Usha Devi. 2009. "Role of Traditional and Online Media in the 12th General Election, Malaysia." Journal of the South East Asia Research Centre for Communications and Humanities 1, 1: 35-58.

Resnick, Danielle. 2012. "Opposition Parties and the Urban Poor in African Democracies." Comparative Political Studies 45, 11: 1351-1378.

Saravanamuttu, Johan. 2001. "Is There a Politics of the Malaysian Middle Class?" In Southeast Asian Middle Classes: Prospects for Social Change and Democratisation, ed. A. Rahman Embong, 103-118. Bangi: Penerbit Universiti Kebangsaaan Malaysia.

Saw, Swee Hock. 2007. The Population of Malaysia. Singapore: ISEAS Publishing. 
Shmuelevitz, Aryeh. 1996. "Urbanization and Voting for the Turkish Parliament." Middle Eastern Studies 32, 2: 162-176.

Sim, Kwang Yang. 2010. "The Cesspool of Sarawak Politics." Hornbill Unleashed, February 10. http://hornbillunleashed.wordpress.com/2010/12 /13/12707/ (accessed October 13, 2013).

The Star. 2013. "More of a 'Malaysian and Urban' Tsunami, Says Kit Siang." May 20. www.thestar.com.my/News/Community/2013/05/20/More-of-a -Malaysian-and-urban-tsunami-says-Kit-Siang.aspx (accessed October 20, 2013).

Thompson, Eric C. 2013. "Urban Cosmopolitan Chauvinism and the Politics of Rural Identity." In Cleavage, Connection and Conflict in Rural, Urban and Contemporary Asia, ed. Tim Bunnell, D. Parthasarathy, and Eric C. Thompson, 161-179. Dordrecht, Netherlands: Springer.

Ufen, Andreas. 2009. "The Transformation of Political Party Opposition in Malaysia and Its Implications for the Electoral Authoritarian Regime." Democratization 16, 3: 604-627.

van de Walle, Nicolas. 2007. "Meet the New Boss, Same as the Old Boss? The Evolution of Political Clientelism in Africa." In Patrons, Clients, and Policies: Patterns of Democratic Accountability and Political Competition, ed. H. Kitschelt and S. Wilkinson, 50-67. New York: Cambridge University Press.

Weber, Max. 1978. "Urbanisation and Social Structure in the Ancient World." In Weber: Selections in Translation, ed. W. G. Runciman, trans. Eric Matthews. Cambridge, UK: Cambridge University Press.

Welsh, Bridget. 2013. "Malaysia's Election and Najib's Challenged Mandate." Asia Pacific Bulletin, 216: 1-2.

Whitby, Kenny J. 1985. "Effects of the Interaction Between Race and Urbanization on Votes of Southern Congressmen.” Legislative Studies Quarterly 10, 4: 505-517.

Yaakob, Usman, Tarmiji Masron, and Masami Fujimaki. 2012. "Population Growth and Urbanization in Peninsular Malaysia 1911-2000." Journal of Ritsumeikan Social Sciences and Humanities 4: 79-101.

Yusoff, Muhammad Agus. 2001. "Sabah Politics Under Pairin." Jati 6: 29-48. 